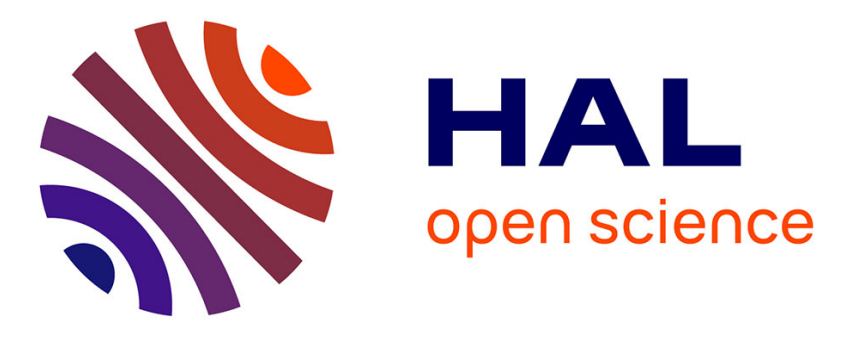

\title{
An Engineer-To-Order Mass Customization Development Framework
}

Jacob Bossen, Michael Natapon Hansson, Ole Madsen, Kjeld Nielsen, Thomas Ditlev Brun $\varnothing$

\section{- To cite this version:}

Jacob Bossen, Michael Natapon Hansson, Ole Madsen, Kjeld Nielsen, Thomas Ditlev Brunø. An Engineer-To-Order Mass Customization Development Framework. IFIP International Conference on Advances in Production Management Systems (APMS), Sep 2014, Ajaccio, France. pp.116-123, 10.1007/978-3-662-44733-8_15. hal-01387156

\section{HAL Id: hal-01387156 https://hal.inria.fr/hal-01387156}

Submitted on 25 Oct 2016

HAL is a multi-disciplinary open access archive for the deposit and dissemination of scientific research documents, whether they are published or not. The documents may come from teaching and research institutions in France or abroad, or from public or private research centers.
L'archive ouverte pluridisciplinaire HAL, est destinée au dépôt et à la diffusion de documents scientifiques de niveau recherche, publiés ou non, émanant des établissements d'enseignement et de recherche français ou étrangers, des laboratoires publics ou privés.

\section{(c)(1)}

Distributed under a Creative Commons Attribution| 4.0 International License 


\title{
An Engineer-To-Order Mass Customization Development Framework
}

\author{
Jacob Bossen, Michael N. Hansson, Ole Madsen, Kjeld Nielsen, and \\ Thomas D. Brunø \\ Department of Mechanical and Manufacturing Engineering, Aalborg University, \\ Denmark \\ jacobbossen@gmail.com
}

\begin{abstract}
Developers of automated manufacturing systems are often categorised as Engineer-To-Order companies, relying on the ability to offer solutions that are tailored to the individual consumer. Managing product variety and enabling reusability between solutions becomes key concepts towards increasing competitiveness and revenue, in which Engineer-To-Order companies may benefit from adopting Mass Customization concepts. As automated manufacturing systems tends to be software intensive, it become equally important to enable reusability for physical components and for software related artefacts. In parallel to Mass Customization, Software Product Line Engineering has emerged as a way for software developers to manage variability and reusability. This paper seeks to combine the concepts of Mass Customization and Software Product Line Engineering, by introducing a development framework applicable for Engineer-To-Order companies offering automated manufacturing systems.
\end{abstract}

Keywords: Mass Customization, Software Product Line Engineering, Engineer-To-Order, Software Intensive Manufacturing Systems

\section{Introduction}

According to the manifesto presented at the latest MCPC conference in Aalborg, Denmark: "the era of Mass Production is over" [13]. This is a widely supported statement, and Kumar [10] even emphasises it further by stating that companies will be struggling for survival, if they do not adapt their strategy to the structural changes in markets. The major structural changes is - in this context - the demand for shorter time-to-market, increased product variety and reduced cost. With regards to manufacturing, the increasing demand for product variety will force a definitive shift in the manufacturing paradigm from Mass Production (economy of scale) towards Mass Customization (economy of scope) and Mass Personalisation (value differentiation) [6].

Products from traditional Engineer-To-Order businesses (ETOs) are similar to products from the pre-Mass Production paradigm, where each product was tailored to the individual customer. The production methods have been developed since, but in principle they still suffer under the labour intensive work 
compared to other product types. For high wage countries, the ETO products are hence cost expensive to produce, since a lot of resources must be allocated to the engineering related aspects of production, and keeps the ETO businesses under a rising pressure in a global competitive market. This has triggered some of the ETOs to standardise their engineering work, and either offer less variety, or instead offer variety in a Mass Customization approach. By offering less product variety, the ETO is though compromising with their business foundation.

This paper is based on a case of a Danish manufacturing systems developer, who offer fully automated robotic solutions for surface treatment. To cope with their customers' high demand for product variety, the company offers completely tailored and high technology solutions that are cost expensive with regards to development time. The company has until now been first movers with regards to technology, but the cost expensive development creates a rising competitive environment, as competitors catch up with the technology. The issue of obtaining a more cost effective development process - while still being able to offer similar product variety as they do currently - is in many ways similar to, what moves companies in other domain towards Mass Customization and Mass Personalisation research. The research question of this paper is hence summarised to: "How can Mass Customization capabilities be utilised with regards to creating an efficient development process for ETOs with software intensive products?" The question is answered through a literature study on Mass Customization and ETO products together with a proposal of a development framework that links concepts found in the literature.

\section{Related Work}

Traditional ETO products are similar to personalised products in the sense, that the scope is to develop customer specific solutions. Talking about Mass Customization and Mass Personalisation, the scope is however also to do it at costs similar to Mass Production [6], which bring us to the scope of the next generation ETO products. To distinguished Mass Customization and Mass Personalisation, work by Bossen and Hansson [2] proposed to see a a mass personalised product as a product, where the user can design the product in collaboration with the manufacturer (co-created product) given continuous freedom within predefined boundaries (personalised modules), combined with freedom of choice (customised modules) and company decided fixed choices (common modules). In other words, Mass Personalisation is a variant of Mass Customization, and hence it is reasonable to say, that the majority of Mass Customization research is relevant for mass personalised products and modern cost efficient ETO products.

Mass Customization has over the years been defined in different ways but work from Salvador et al. [15] summarise it to "Providing customers what they want when they want". The same authors emphasise that in practice, the implementation of a Mass Customization strategy must not be seen as the destination for the company, but rather a process that will never end. In the same work, the authors defines Mass Customization as having three common capabilities, 
which every mass customiser to some extent must posses. These three capabilities are defined as: "(1) the ability to identify the product attributes along which customer needs diverge, (2) the ability to reuse or recombine existing organisational and value-chain resources and (3) the ability to help customers identify or build solutions to their own needs." The capabilities are called Solution Space Development, Robust Process Design and Choice Navigation respectively. Each one of them has been proven to be essential to be a mass customiser but few companies can claim to posses them all to perfection.

The transition from mass producer to a mass customiser is discussed exhaustively in literature, but the relevancy of moving an ETO business to a Mass Customization business is somehow less debated. However, work done by Haug et al. [4] focus on this issue, and the conclusion is, that even though not all definitions of Mass Customization includes an ETO business - and that an ETO business will never produce end-products near Mass Customization cost - it is still reasonable to label some of them as mass customisers. The authors claim that an ETO business must divide the development process into work packages which in some cases can be fully or partly automated (separation of concerns). This creates a need for standardising the engineering work to a partly predefined solution space, and a consistent specification process that supports customer cocreation in the development process.

As the company - which this paper is based on - develops automated manufacturing systems that are highly software intensive, another important aspect is to understand how Mass Customization is applicable to software development.

Much like the producers of physical goods, software producers have been looking towards means to avoid developing software systems from scratch, and instead, developing software product lines with reusable parts that can be shared across a product line. One of the paradigms is referred to as Software Product Line Engineering (SPLE), and is based on the principles of Mass Customization [14]. An important aspect to SPLE is the separation in development process between the establishing of the platform and reusable parts, and the derivation of the individual products with the product specific parts [3]. Pohl et al. [14] and Apel et al. [1] separates the development process even further into aspects concerning requirement establishment and realisation, and suggest a framework for implementation. The general separation of concerns principle links quite well to work on Mass Customization and ETO products by Haug et al. [4].

One of the key challenges with the SPLE approach and ETO products is to cope with the transition from ETO to Mass Customization. According to Krueger [9] there are three adoption approaches to initiate the transition; a proactive approach, an extractive approach, and a reactive approach. The proactive approach can be described as a big-bang design strategy [5], where product lines are developed from scratch and follows a step-by-step waterfall approach to design and implement a product line [9]. The extractive approach is a refactoring strategy [17], where the goal is to structure the existing legacy solutions in a companies product portfolio in a more systematic way [9]. The reactive approach is an evolution design strategy, where an initial version of product line is 
designed and implemented, and gradually extending and redesigning the product line to cover more products [1].

All of the approaches have advantages and disadvantages, but for small software ETOs the extractive approach seems beneficial because the incremental adoption also yields a lower upfront investment compared to the proactive approach. This is in general because the extraction process may only concern focusing on specific parts of the product and incrementally including more parts [17]. The downside of the extractive approach is, that implementation of the product line is potentially limited by the structure and code practises of the legacy products, since these not necessarily was implemented in structured way. This limitation means, that the refactoring process do not result in an easy maintainable structuring of the product line [1].

\subsection{Research Gap}

Based on the related work identified in section 2, it can be concluded that SPLE can be used for ETO companies developing software intensive manufacturing systems. Furthermore, since SPLE originally builds on Mass Customization and basically treat the same purpose, this paper assumes that the three fundamental capabilities of Mass Customization can be linked to SPLE, and thereby enable use of research from SPLE and vice versa. One example is the performance assessment research that is essential for continues improvement of the capabilities.

We conclude that a need for a ETO Mass Customization developing framework - that links the Mass Customization capabilities and SPLE - exist.

\section{Mass Customization Development Framework for ETO Businesses}

With basis in the essential capabilities of Mass Customization and development concepts from SPLE, we propose a product development framework for ETO product developers (see figure 1). The framework is divided according to activities related to each of the Mass Customization capabilities, and the distinctive engineering aspects. This differentiation separates the concerns of developing end-products, developing the product line, and the extraction of the potential reusable legacy artefacts. These aspects are referred to as Application Engineering, Domain Engineering and Reverse Engineering respectively. The aspect of Domain and Application Engineering are basic aspects of SPLE, whereas the aspect of Reverse Engineering is included, in order to emphasise the continues evolution of the product line through legacy reuse. Hence this framework has a focus on transforming personalised/product specific parts into reusable artefacts. In order to support continuous improvement of capabilities, we have with inspiration from Kristal et al. [8] and Nielsen [11] - included Performance Assessment in the framework as a supporting capability. By including it as a capability of the framework, we underline the need for research addressing how to conduct Performance Assessment in this context. 


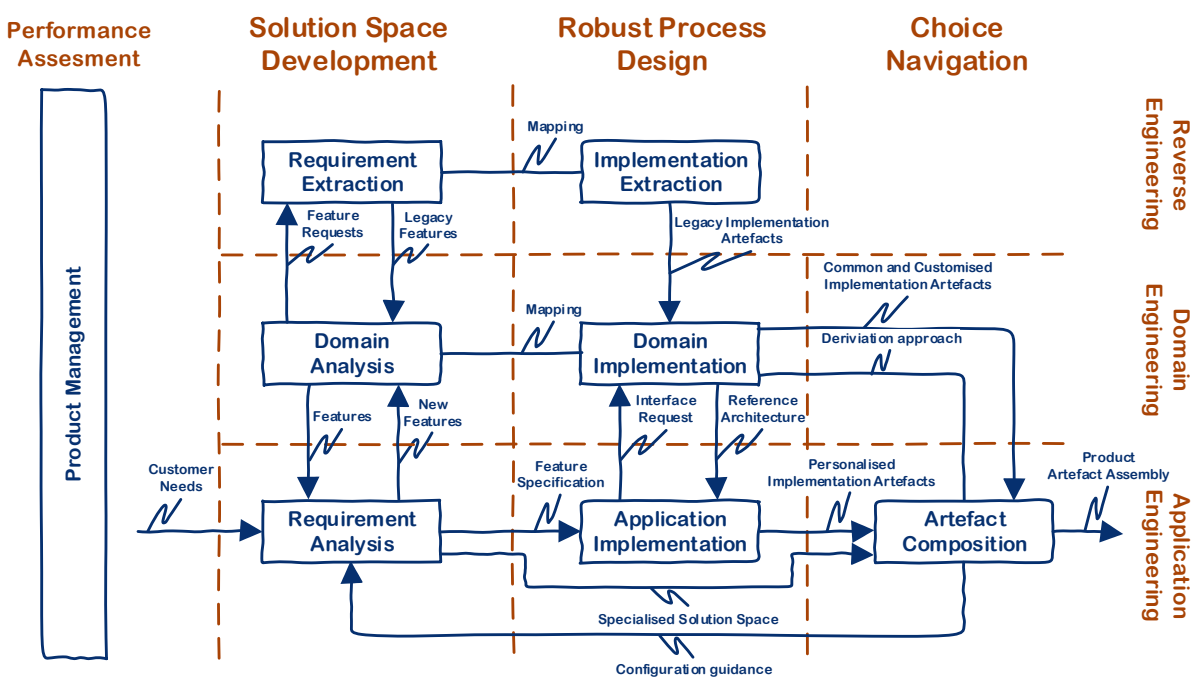

Fig. 1. Mass Customization development framework for ETO businesses

Furthermore we emphasise, that the proposed framework is seen from a development viewpoint, which has similarities to the non-traditional Mass Customization process view from Haug et al. [4]. In general we believe that Mass Customization must be seen from one or more product views and several process views. Examples of process views is for instance sales, development and commissioning, where this paper focus on the development viewpoint.

\subsection{Solution Space Development}

Solution Space Development is about understanding and managing the behavioural requirements for the product that are derived from customer needs. The actual process of identifying the customer needs are though not a part of Solution Space Development in the framework, since we believe this activity is allocated to a sales view-point. The focus of Solution Space Development is therefore to align customer needs to solution space and vice versa. This correlates with the original intention of Solution Space Development from section 2 besides the development of customer needs. Solution Space Development is conducted by expressing and managing communality and variability in terms which are understandable for developers but not necessarily for customers. This correlates with Kang and Lee [7]. A popular SPLE approach in this context is to express needs according to features, which may be defined as a behavioural product functionality that originates from a specific customer need [1].

As in traditional SPLE, the framework includes the aspect of Application Engineering and Domain Engineering. Together these continuously cover the processes of analysing if 1) a feature already exist as a reusable artefact, 2) a new feature should be developed as a reusable artefact, or 3) a new feature should be developed as a product specific artefact [14]. For ETO companies, the 
entire business strategy relies on tailoring end-products with customer specific features, which in most cases will involve constantly extending the end-products with features that are not already developed. A vital aspect for ETO companies in Solution Space Development is hence, the ability to recover any product specific features from legacy products, that may resemble the possible new features derived from the Requirement Analysis in the Application Engineering aspect. This requires, that the company is able to acquire knowledge, regarding whether or not a customer specific feature already exits in the solution space. This is related to the aspect of Reverse Engineering, and the supporting capability Performance Assessment.

\subsection{Robust Process Design}

From a development view-point, Robust Process Design concerns the actual realisation of the features identified in the solution space. Robust Process Design is focussing on continuously improving the product related artefacts, in order to identify, if they may be reused or recombined into a stream of different endproducts. This involves consideration towards how communality and variability is implemented, but also when variability is implemented.

Both in traditional Mass Customization and SPLE, architecture- and platform development are vital processes to secure reusability and managing variability which are related to the Domain Engineering aspect [3]. Since the demand for product specific parts are higher for ETO companies, it is important to allow the architecture to be extended with the product specific parts developed during Application Engineering. This may be handled by a static- or dynamic approach. The static approach involves clearly specifying where variation points exits in the architecture in order to interface product specific parts. The dynamic approach may be viewed as a contentiously evolution of the architecture to address the integration of product specific parts. Whether the static or dynamic approach is used, it always involves implementing variation points in the platform or in the customisable parts of the architecture. These implementations must however be monitored to justify the relevancy of the variation point in the future, and is related to Performance Assessment.

As product specific parts continuously grow in numbers - in form of legacy products - an important ability for software ETOs, is to reuse existing implementation solution if possible. This is related to the Reverse Engineering aspect. However, the intention is not to force developers to extract, and refactor product specific parts from legacy products, if the integration process is difficult. Therefore, an equally important ability in robust process design, is to access whether or not refactoring legacy products is worthwhile in the current situation, or if it will be more beneficial to develop from scratch.

\subsection{Choice Navigation}

In the product development view-point, choice navigation concerns the process of assisting the developer in configuring the end-product that satisfies the re- 
quirements of the customer. This may involve assisting tools such as a configurators or procedural specifications, to navigate the developer towards deriving an end-product. Depending on the production tools, the process of creating an endproduct may either be conducted manually, automatically, or in a combination of both.

\section{Discussion}

By introducing the Performance Assessment supporting capability, a development team has the possibility to monitor how e.g. a Mass Customization transition process is advancing. This activity is called Product Management in the framework, and is responsible for collecting, measuring and calculating Performance Assessment data. The Mass Customization performance assessment research from Nielsen et al. [12] is useful here, but also the linking of Mass Customization and quality management from Kristal et al. [8] and Storbjerg et al. [16] is highly relevant. Possible implications by using Performance Assessment is for instance - but not limited to - the ability to measure profitability. Profitability may in this context be linked to the decision of when to include a new feature to the product line, based on the frequency of a specific personalised feature use.

By introducing view-points, it is envisioned that the Mass Customization capabilities are utilised in multiple stages of the production process besides the development view-point. For developers of automated manufacturing systems, a vital process is the actual integration of the solution in the production environment, which requires an effective commissioning process. How the Mass Customization capabilities are utilised in the different view-points, and how many process view-points that exist, must therefore be further investigated.

\section{Conclusion}

The literature study shows that SPLE research achievements are highly relevant for ETO companies developing software intensive manufacturing systems, and that SPLE and Mass Customization originally was developed with the same purpose in mind. The research gap from section 2.1 concludes, that if a framework - which links the two research areas - is developed, then contributions from both areas can be used to bring the Mass Customization research further, with regards to software intensive products. Especially the Mass Customization Performance Assessment research is relevant in order to continuously improve the process of a successful Mass Customization implementation process. This paper proposes a framework addressing how ETOs could develop software intensive products, hence the applicability of the framework will initially mainly address the software related artefacts of the product. Therefore, further research must be conducted to show if the framework has limitations with regards to more hardware intensive systems. 


\section{References}

[1] Apel, S., Batory, D., Kästner, C., Saake, G.: Feature-Oriented Software Product Lines. Springer Berlin Heidelberg (2013)

[2] Bossen, J., Hansson, M.N.: Realizing mass personalization (2013), unpublished

[3] Clements, P.C., Northrop, L.: Software Product Lines: Practices and Patterns. SEI Series in Software Engineering, Addison-Wesley (2001)

[4] Haug, A., Ladeby, K., Edwards, K.: From engineer-to-order to mass customization. Management Research News 32(7), 633-644 (2009)

[5] Heradio, R., Fernandez-Amoros, D., de la Torre, L., Abad, I.: Exemplar driven development of software product lines. Expert Systems with Applications 39(17), 12885 - 12896 (2012)

[6] Hu, S.J.: Evolving paradigms of manufacturing: From mass production to mass customization and personalization. Forty Sixth CIRP Conference on Manufacturing Systems 7, 3-8 (2013)

[7] Kang, K., Lee, H.: Variability modeling. In: Capilla, R., Bosch, J., Kang, K.C. (eds.) Systems and Software Variability Management, pp. 25-42. Springer Berlin Heidelberg (2013)

[8] Kristal, M., Huang, X., Schroeder, R.: The effect of quality management on mass customization capability. International Journal of Operations and Production Management 30(9), 900-922 (2010)

[9] Krueger, C.W.: Easing the transition to software mass customization. In: Linden, F. (ed.) Software Product-Family Engineering, vol. 2290, pp. 282293. Springer Berlin Heidelberg (2002)

[10] Kumar, A.: From mass customization to mass personalization: a strategic transformation. International Journal of Flexible Manufacturing Systems 19(4), 533-547 (2007)

[11] Nielsen, K.: Mass Customization Assessment And Measurement Framework For Industrial Applications. Department of Mechanical and Manufacturing Engineering (2014)

[12] Nielsen, K., Brunoe, T.D., Joergensen, K.A., Taps, S.B.: Mass customization measurements metrics. In: Proceedings of the 7th World Conference on Mass Customization, Personalization, and Co-Creation. pp. 359-375 (2014)

[13] Pine, J.B.: The mass customization manifesto. Unpublished (2014)

[14] Pohl, K., Böckle, G., van der Linden, F.: Software Product Line Engineering. Springer Berlin Heidelberg (2005)

[15] Salvador, F., de Holan, P.M., Piller, F.: Cracking the code of mass customization. MIT Sloan Management Review 50(3), 71-78 (2009)

[16] Storbjerg, S., Brunoe, T., Nielsen, K.: Mass customization and performance assessment: Overview and research directions. In: Proceedings of the 7th World Conference on Mass Customization, Personalization, and Co-Creation. pp. 333-347 (2014)

[17] Zhang, G., Shen, L., Peng, X., Xing, Z., Zhao, W.: Incremental and iterative reengineering towards software product line: An industrial case study. In: Software Maintenance (ICSM), 2011 27th IEEE International Conference on. pp. 418-427 (Sept 2011) 